\title{
Changing trends of maternal death $-A$ five years study in a rural medical college in India.
}

\author{
Dr. Shibram Chattopadhyay, Dr. Dilip Biswas, Dr. Narayan Jana, \\ Dr. Apurba Mondal, Dr. Debobroto Roy, Dr. Shritanu Bhattacharyya \\ Associate Professor, dept. of G\&O NRSMCH, Kolkata. \\ Assistant Professor, Dept. of G\&O, Burdwan Medical College, West Bengal. \\ Professor G\&O,, Burrdwan Medical college,W.B. \\ Assistant Professor, G\&O, NRSMCH,Kolkata. \\ RMO cum Clinical tutor, G\&O Burdwan Medical College, W.B. \\ Professor G\&O, NRSMCH, Kolkata.
}

\begin{abstract}
:
Aims: To analyze the maternal mortality with its causes and it's possible contributing risks factors at Burdwan Medical College Burdwan, West Bengal. Setting \&Design: This study was carried out at Obstetrics and Gynecology department of Burdwan medical College from January 2009 to December 2013. This is a retrospective case series study. Methods \& Materials: This study was conducted by analyzing death records of all maternal death that died over period of five years from January 2009 to December 2013. The demographic record included age, parity, booking status and education, the cause of death and possible contributing factors were evaluated. Concslusion: Eclampsia, hemorrhage and Sepsis are still the major killers. Factors which need urgent improvement include education, antenatal booking, early diagnosis and referral to tertiary care centre.
\end{abstract}

Key words: Maternal mortality, Eclampsia, Hemorrhage, Sepsis.

\section{Introduction}

Maternal death, according to ICD-10 issued by WHO is defined as "death of a woman while pregnant or within 42 days of termination of pregnancy, irrespective of duration and the site of pregnancy, from any cause related to or aggravated by the pregnancy or its management but not from accidental or incidental causes"12. Maternal mortality rate (MMR) is expressed in terms of such maternal deaths per 1, 00,000 live births.

About half a million women die each year due to pregnancy related complications and $95 \%$ of these come from developing countries. ${ }^{3}$ The major causes of maternal mortality are hypertensive disorders, hemorrhages, sepsis, obstructed labor and unsafe induced abortion.

\section{Methods and materials}

This retrospective study was carried in Obstetrics and Gynecology department of Burdwan Medical College over the period of five years i.e. Jan 2009 to December 2013.Burdwan is a district town located approximately $100 \mathrm{~km}$. from Kolkata, capital of West Bengal India. This is a tertiary care teaching hospital with 1105 beds with more than 20,000 deliveries conducted every year. The records of all maternal death were collected from labor ward register, obstetric ward and operation theatre register. The demographic data of each patient including age, parity, educational status, whether booked or unbooked were reviewed. Mode of delivery was noted i.e. whether vaginal or $\mathrm{C}$-section. In our hospital vaginal deliveries were usually conducted by interns, house-staffs, post graduate trainee and residential medical officers while for a cesarean section always a senior doctor like clinical tutor or assistant professor was called upon. Finally the cause of death was recorded. The total deliveries of the study period were collected from labor records. The study specially emphasized on rate of maternal death, causes, interval from admission to death and ages of the patient. The purpose of our study was to assess the health care status and to analyze the causes of death.

\section{Results}

Direct causes of maternal deaths are those resulting from complications of pregnancy, delivery and their management. Indirect causes include conditions present before or developed during pregnancy but aggravated by the physiological effects of pregnancy or strain during labor.

A total of 1, 10,550 deliveries took place during this period and 352 maternal deaths were recorded making MMR of 329/100,000 live births. All the mothers were uneducated except 100 who had completed their 
primary education. The majority of the cases were resident of district Burdwan and adjacent districts of West Bengal like Birbhum, Bankura, and Hooghly.

Table 1 . shows that amongst the maternal death $42 \%$ were teenage pregnancy and $41 \%$ were between 20 to 30 years age group.

Direct cause contributed to $85 \%(93,967)$ of maternal deaths the commonest being hypertensive disorder $37 \%(40,903)$ fallowed by sepsis $28 \%(30,954)$ and hemorrhage $19 \%(11,055)$.

$15 \%$ (52) of maternal deaths had indirect cause's hepatic encephalopathy, anemia, renal failure due to hypovolemia in spinal anesthesia and heart disease.

Among all above maternal deaths 87 had emergency c-section done and 203 delivered vaginally. 41 cases were already delivered when they arrived at our unit. 20 cases did not deliver at all as they died within 4hours of arrival at our hospital.

\section{Discussion}

Pregnancy is not a disease and morbidity and mortality related it is preventable. According to WHO, maternal mortality is an important measure of a women's health and indicative of the performance of health care system. Unfortunately, there is a big divide between developed and developing world on the score of maternal mortality. Developed countries have MMR of around 20/100,000 while countries like Afghanistan the figure is $1600 / 100,000$.

According to national health survey of India the MMR of country is 400/100,000 live births but the figure could still be higher as there is no systemic reporting of maternal mortality especially in rural areas.

The MMR in our study was 329/100,000 live births which is quite comparable with the studies carried in big tertiary hospitals in West Bengal of India. The high MMR of our study is because of the fact that our hospital receives mostly the cases which are usually un-booked and late referrals. Many times the patients die on their way to the hospital because of transport problems. In our study the indirect causes contributing to maternal death were $15 \%$ which is very similar studies in India. Among indirect causes, anemia was the most common cause, the fact that still in rural areas the poverty and malnutrition are very rampant.

Hypertensive disease remained the most common cause (37\%) of maternal death which is same as shown by Hassan et al and Nusrat. This is in contrast with the results from other studies which showed hemorrhage to the leading cause of maternal death. Among the hemorrhagic causes of maternal death abortion related death is important.

Sepsis came out to be the second most common cause (28\%).the high incidence of sepsis is due to the fact that a good number of patients referred to this hospital with abortion done by illiterate quack practitioner.

This result of this study is in contrast in developed countries where sepsis is no more a leading cause of maternal mortality in developed countries

Hemorrhage was the third leading cause (19\%) of maternal death in our hospital. The decline in death due to hemorrhage may be due to the fact that we have now introduced the active management of labor and wider use of prostaglandin as a utero-tonic agent.

Most of deaths (42\%) occurred in women who were below 20 years of age. Highest mortality was seen in primigravidas.

In India MMR (400) is alarming. Reducing maternal mortality by 2015 is part of millennium development goals (MDG) set forth by International community and endorsed by government of India, by virtue of which we are committed to reach the stated target in the next five years. According to Regional health forum, the three delays increase the risk to a woman's life i.e. delay in deciding to seek care, delay in reaching a medical facility and delay in receiving quality care at facility.

The MMR in Srilanka has declined from 630 in 1948 to 57 in 2000. This gain is achieved by improving female education, women empowerment and availability of emergency obstetric care. In India poor education, poverty and cultural setup are the major factors which need to be given serious attention.

\section{Conclusion}

The maternal mortality rate in our study is still now very much higher than the national data but is declining now. Our recommendations to improve the health status of pregnant women and to diminish the maternal mortality are the followings:

1. Special emphasis on antenatal care and iron and folic acid prophylaxis

2. Improvement of transport facilities for early referral

3. To give much more attention during labor and delivery and to improve post partum care.

4. To improve $\mathrm{MCH}$ and $\mathrm{EMOC}$ care at community level

5. Improvement of blood transfusion network.

6. Adolescent health care and improvement of socioeconomic status and woman empowerment.

7. Control of medical termination of pregnancy to reduce unsafe abortion. 
8. Availability of senior consultants including skilled obstetrician/ expert anesthetist and trained staff round the clock will also reduce MMR.

9. Training of doctors, lady health visitor's, midwives and local dai through workshops with regards to family planning, antenatal care, eclampsia, clean safe delivery and emergency obstetric care will help to reduce maternal mortality to great extent.

\section{Acknowledgement}

The authors are grateful to Medical superintendent cum vice Principal of Burdwan Medical College to conduct the study.

\section{References}

[1]. Maternal Mortality in 2000. Estimates developed by WHO, UNICEF and UNFPA, Geneva, Switzerland, WHO; 2004.

[2]. Onah HE, Okara JM, Umh U, Chigbu CO. Maternal mortality in health institution with emergency obstetric care facilities in Enu gu state, Nigeria. J Obstet Gynecal 2005; 25:569-74.

[3]. India Millennium Development Goals report 2006. Planning commission, Govt. of India.

[4]. Annual report family health. Colombo, SriLanka: evaluation unit, family health bureau, ministry of health,2000.

[5]. Deaths attributable to childbearing in Matlab, Bangladesh: Indirect causes of Maternal Mortality Questioned, American Journal of Epidemiology 2000 Vol 151(3):300-306.

[6]. Maternal Mortality- A retrospective analysis of Ten years in a tertiary hospital M. Jain,Silajee Maharahji, Indian J. Prev. Soc. Med., 34 No.324,2003.

[7]. Review of Changing trends in maternal mortality in a rural medical college in West Bengal, Pal Amitava, Ray Prasanta,Hazra Samir,Mondal T.K, J Obstet Gynecol India Vol.55,No.6; November/December 2005 Pg 521-524.

[8]. Analysis of causes of maternal death in eclampsia, A, Khan, A Ghosh, P. K. Banerjee, T.K.Mondal, e-ISSN:2279-0853 pISSN:2279-0861,Vol-13,Issue3 VER -VI,(March-2014), PP 07-10.

[9]. Mahajan and Gupta's Textbook of Preventive and Social Medicine,Chapter-30,PageAuthor Roy Nath Rabindra and Saha Indranil.

[10]. Bhattacharya S K, Majhi A K, Seal S L, Mukhopadhyay S, Kamilya G, Mukherji J, Maternal Mortality in India; a 20 years study from a large referral medical college hospital, West Bengal. J obstet Gynaecol Res 2008Aug;(4);499-503

[11]. Park's textbook of preventive and social medicine: $19^{\text {th }}$ edition pg444-448

Table 1

Relationship of age with maternal mortality.

\begin{tabular}{ll}
\hline Age(years) & n(no. of cases) \\
\hline$<20$ & $147(42 \%)$ \\
$20-30$ & $143(41 \%)$ \\
$31-40$ & $54 \quad(15 \%)$ \\
$41+$ & $8 \quad(2 \%)$ \\
total & 352 \\
\hline
\end{tabular}

Table 2

Relationship of parity with maternal mortality

\begin{tabular}{ll}
\hline Parity & N(no. of cases) \\
\hline 0 & $182(52 \%)$ \\
$1-3$ & $157(45 \%)$ \\
$4+$ & $12(3 \%)$ \\
\hline & 352
\end{tabular}

Table no.3

\begin{tabular}{|l|l|l|l|}
\hline year & Maternal death & Live birth & $\begin{array}{l}\text { Maternal death/1,00,000 } \\
\text { live births }\end{array}$ \\
\hline 2009 & 91 & 13017 & 699 \\
\hline 2010 & 86 & 13786 & 623 \\
\hline 2011 & 72 & 14296 & 503 \\
\hline 2012 & 64 & 13453 & 475 \\
\hline 2013 & 39 & 12133 & 321 \\
\hline 352 &
\end{tabular}


Table 4

Causes of maternal mortality: Direct causes $(85 \%)$

\begin{tabular}{|c|c|}
\hline Causes of death & $\mathrm{N}$ (no. of death) \\
\hline Hypertensive disorder & $129(43 \%)$ \\
\hline sepsis & $105(35 \%)$ \\
\hline hemorrhage & $66(22 \%)$ \\
\hline Total & 300 \\
\hline \multicolumn{2}{|c|}{ Table 5} \\
\hline Causes of death: & (no. of deaths) \\
\hline Hepatic encephalopathy & $7 \quad(14 \%)$ \\
\hline anemia & $18(35 \%)$ \\
\hline Renal failure & $15(29 \%)$ \\
\hline Heart disease & $7 \quad(13 \%)$ \\
\hline Pulmonary tuberculosis & 5 (9\%) \\
\hline Total no. of deaths & 52 \\
\hline
\end{tabular}

Table 6:

Mode of delivery

Mode of delivery

Emergency cesarean section

$\mathrm{N}$ ( no. of patients)

Vaginal delivery

$87(25 \%)$

Delivered outside

$203(58 \%)$

Did not deliver

$20 \quad(5 \%)$

Total

352

Table no. 6

Time interval

maternal death

$<24$ hours

24 hours to 7 days

$84(24 \%)$

More than 7 days

$204(58 \%)$

Total no. maternal deaths

$63(18 \%)$

352 